\title{
NUEVOS AMBIENTES DE APRENDIZAJE MEDIANTE TECNOLOGÍAS DIGITALES EN LA UNI - NORTE
}

Lic. Rigoberto Morales

Correo: Rigoberto.Morales@norte.uni.edu.ni

Coordinador de CC.BB

UNI - Norte

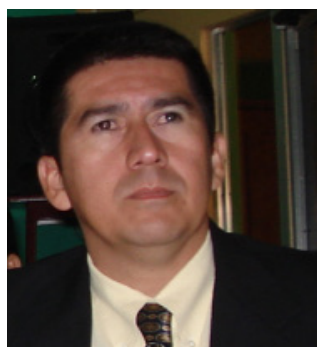

Durante mi experiencia como docente y como técnico en el Ministerio de Educación, pude observar la lucha de las diferentes autoridades educativas para lograr insertar, en los programas educativos modernos, la informática, con la finalidad de enriquecer el aprendizaje de las futuras generaciones y romper con la enseñanza tradicional.

Cuando el Ministerio de Educación planteaba, en los talleres o capacitaciones, la idea de impartir la enseñanza haciendo uso de computadoras, las reacciones de escepticismo de parte de los docentes de aula no se hacía esperar, y por supuesto que los precursores del saber no estaban equivocados ni tampoco pretendían sabotear la propuesta, solamente era que no había concordancia entre la idea y los medios y puedo decir hasta con el contexto socioeconómico del momento.

Al paso del tiempo, nuestra juventud se fue apropiando de la tecnología de diversas maneras en los llamados Cybers, donde se vende el uso de computadoras. Algunos centros de estudios estatales y escuelas normales fueron favorecidos con una cantidad de computadoras para ser usadas por los estudiantes y en algunos centros privados fueron incorporando en sus programas la clase de computación. El fin era, hacer más llamativa la oferta académica. Pero esta idea se ha limitado solamente al área del uso y manejo de las computadoras y no se ha extendido a las demás asignaturas. Por lo tanto se puede estar cayendo en un inapropiado uso de las computadoras, provocando un desaprovechamiento de los medios tecnológicos con una rutina que con el tiempo puede generar una ignorancia tecnológica.

El uso de la computadora no puede verse como una moda, sino como un recurso que puede influir en el modo de actuar del profesional. La computadora hace más placentero el aprendizaje y constituye una emulación "hombre máquina" que redunda en beneficio del propio estudiante.
Aunque el medio audiovisual lleve implícito el método, si éste está mal dirigido en su uso, no cumpla con eficiencia en los objetivos planteados. Se impone la armonía en el empleo de medios y métodos que intensifiquen el proceso docente educativo, elevando su eficiencia y calidad.

Pero no todo es negativo, el dominio de los recursos audiovisuales te enriquece y puede llegar a convertirte en un docente o estudiante competitivo, moderno y dinámico. El modelo Educativo Institucional de la UNI concibe la Educación en su sentido amplio, como un proceso permanente, sistémico, sistemático y transformador del ser humano y la sociedad. Los egresados de la universidad serán capaces de aportar sus conocimientos, habilidades y valores a ese cambio tan necesario de las políticas públicas de la sociedad.

\section{¿En qué consiste una multimedia Educativa?}

Multimedia, en su definición más extensa, es la presentación de la información que emplea la combinación de medios: texto, animaciones, imágenes, sonidos y videos. Es una colección de tecnologías basadas en la utilización de la computadora, da al usuario la capacidad de acceder y procesar información. Cuando se permite al usuario controlar ciertos elementos y el momento en que deben presentarse, se le llama Multimedia Interactiva.

Los estudios han demostrado que los entornos de enseñanza interactivos bajo la supervisión de instructores, igual que los tutoriales prácticos, son de mucho más ayuda a los estudiantes. Estos cursos interactivos proporcionan vivencias que no las puede proporcionar la lectura de los libros de texto o la visualización de videos.

La creación de la Multimedia data aproximadamente desde 1937 y se ha ido perfeccionando a medida que se 
van descubriendo nuevas herramientas.

La Universidad Nacional de Ingeniería ofrece el uso de multimedia educativa. El docente y el estudiante pueden enriquecer sus conocimientos e intercambiar experiencias. Hemos experimentado con nuestros compañeros docentes y alumnos de la carrera de ingeniería en sistemas, una alternativa innovadora que hará la enseñanza más dinámica y atractiva para los alumnos, y por supuesto del docente que siempre está tratando de enriquecer su trabajo educativo. La creación de multimedia educativa en el área de física y matemática permite a estudiantes y docentes la expresión de nuevas ideas, integrando aportes y vivencias para enriquecer el conocimiento intelectual.

\section{¿Cómo surge la idea de la creación de la Multime- dia Educativa en la sede?}

Surge de igual manera que la UNI Norte, a partir de las mismas necesidades de la población educativa de la sede. Un equipo de tres docentes, (Licda. Graciela López, Licda. Alba Mara Úbeda y Licdo. Rigoberto Morales Videa) consideramos en el 2008 la idea de trabajar en la creación de multimedia educativa para la enseñanza de física y matemáticas en la secundaria. Establecer el método de aprendizaje para facilitar el intercambio de experiencias y el auto aprendizaje. Imprimir fluidez y eficacia, establecer una estrategia dinámica, enriquecedora y comunitaria, donde el mismo estudiante se convierte en mentor de su aprendizaje, compartiendo sus experiencias y exteriorizando sus habilidades formativas.

Retomamos esta herramienta como medio didáctico, la cual consideramos necesaria para facilitar el aprendizaje de nuestra comunidad educativa, disminuir la deserción escolar en nuestro país, mejorar el uso de los medios que ya existen en centros de estudio de educación media y contribuir con la calidad de la enseñanza, proveyendo a los futuros bachilleres la experiencia en el uso y creación de multimedia.

\section{¿Cómo se conformó el equipo de trabajo?}

Se seleccionó un equipo de estudiantes de la carrera de Ingeniería de Sistemas de primero, segundo y tercer año. Una vez seleccionados, transferimos la idea y se inició un proceso de capacitación e inter capacitación.
Aprendimos a manipular los software Geogebra, Derive 6, y Director MX. Se realizó un diagnóstico para Identificar laboratorios de cómputos existentes en el municipio de Estelí que permitieran el desarrollo de proyectos de multimedia educativas de matemática y física en Educación Media y la población a beneficiarse con éstos. Conformamos dos equipos de trabajo, uno para elaborar la multimedia de física con el tema "Ramas de la Física" y el otro para elaborar el de matemática con el tema "Cuerpos Sólidos"

Una vez conformados los equipos de trabajo, éstos participaron con su proyecto en la Cuarta Feria Cultural, Científica y Tecnológica, celebrada en la sede de la UNI- Norte con el lema ¡Aprender haciendo desde la Educación por competencia! Obteniendo el primer lugar la multimedia de Física y el tercer lugar la multimedia de Matemáticas.

Se destacó en su elaboración el estudiante de tercer año de ingeniería en sistemas el bachiller Norlan López Armas. Quien además de mostrar dedicación y abnegación mostró sus habilidades informáticas de manera extraordinaria.

\section{Ejemplo desarrollado:}

Se hizo una presentación animada donde el alumno pudo observar el concepto de La ley de conservación de la energía. Lo puede interiorizar haciéndolo ejecutable en cada una de sus dimensiones.

El estudiante pudo vivir la experiencia tal cual si estuviera de visita en una planta real, pero puede repetir la experiencia las veces que lo desee.

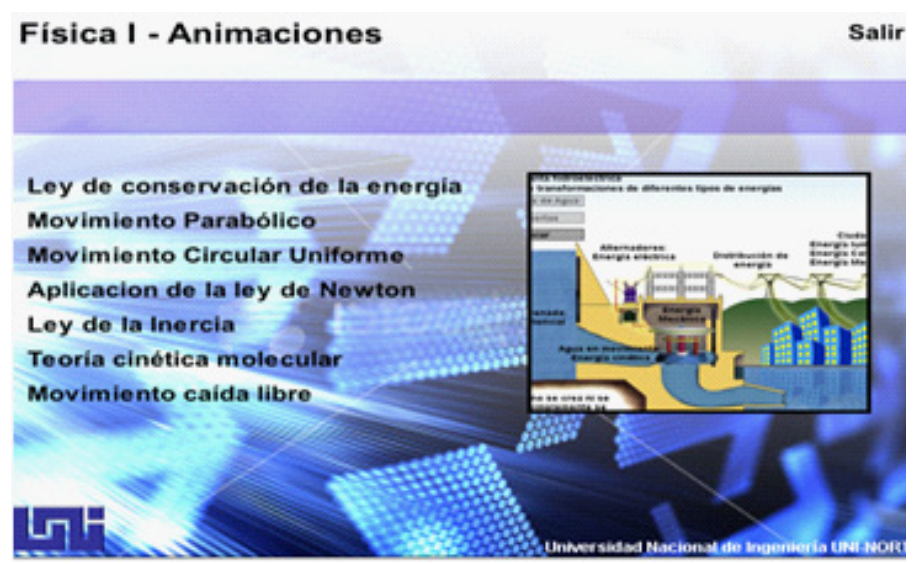

Fig. Interfaz de multimedia Fisica I. 


\section{DE MI EXPERIENCIA PERSONAL}

Lo observado como maestro guía del proyecto es singular. El docente se siente realizado cuando observa a sus alumnos captar la visión y la aplicación de forma espontánea.

Desde el momento de la creación de la multimedia, cada paso dado era un aprendizaje nuevo y lo que faltaba era el día del reto donde ellos quedarían al frente de un jurado que los mediría y los examinaría.

Cada herramienta llevada a cabo por los estudiantes en la conformación de la multimedia reflejaba habilidades que hasta ese momento ellos mismos descubrían. Fue una experiencia que les dió confianza y los estableció con más seguridad en la mística del amor a su carrera.

Con estos resultados nos motivamos y empezamos a elaborar multimedia en el área de Física I, en las unidades de cinemática y dinámica. En Física II, en las unidades de circuitos eléctricos, corriente eléctrica, magnetismo y Ley de Ampere. En Matemática I, en la unidad de geometría analítica vectorial con simulaciones de sistema de coordenadas en R3. Ya están listas para ser usadas desde el inicio del año lectivo 2009.

La elaboración constante de multimedia nos motiva a los docentes a mantenernos más informados, y por lo tanto en llevar, a través de estos medios, aportes científicos de primer orden garantizando el aprendizaje de calidad.

Este método permite al estudiante no solamente ser receptor de conocimientos sino también que aporte sus experiencias u opiniones, rompiendo así con los paradigmas tradicionales y entrando en una etapa de intercambio de conocimientos, contribuyendo con una enseñanza eficaz y convincente.

El uso de multimedia Educativa favorece la interdisciplinaridad con más eficacia que con los métodos tradicionales. Por la importancia que tiene la educación superior en las transformaciones futuras de la sociedad, las universidades juegan un papel protagónico con el desarrollo de programas de investigación, formación, capacitación y actualización de docentes. Los educadores de UNI - NORTE damos inicio a una brecha de amplitud y actualización de conocimiento en las TIC (Tecnología de Información y Comunicación) contemplado en el nuevo Modelo Educativo Institucional (MEI).

Nuestra meta es valorar el impacto y efectividad del uso de las TIC en las capacitaciones, brindar nuevos espacios para que los estudiantes participen y contribuyan en el proyecto, conociendo otras formas de enseñanza y aprendizaje de la Física y la Matemática.

Posteriormente y en concordancia con los resultados de seguimiento y evaluación, haremos extensivo este esfuerzo al Ministerio de Educación, (MINED). Generalizar su uso dentro de la práctica educativa es el objetivo. Los docentes por medio de la inducción recibida, deben valorar la utilidad de las nuevas tecnologías de la información y comunicación en los procesos de la enseñanza y aprendizajes de la física y la matemática.

El colectivo de estudiantes y docentes de la UNI NORTE pretendemos contribuir al mejoramiento y enriquecimiento del aprendizaje de los contenidos curriculares en física y matemática en la Educación Media. La meta debe ser poner en práctica el uso significativo de las TIC y seguir trabajando en esta línea para dar una visión diferente a la práctica pedagógica.

"La tarea de la Educación tiene que ver con el tipo de mundo que queremos vivir" (El sentido de lo Humano, Maturana, 1991: 238)

\section{REFERENCIAS}

Chaveco Juan, r. J. (2004). Multimedia y Software Educativo. Managua: UPONIC.

Ingeniería, u. N. (2008). Modelo Educativo Institucional. Managua: eikön de Nicaragua.

José, p. L. (2004). Aplicaciones informáticas y computacionales. Managua: UPONIC.

Teresa, t. (10 de diciembre de 2003). Incorporación de entornos tecnológicos de aprendizajes. Recuperado el 15 de Julio de 2008, de www.rieoei.org/rie33a07.htm\#a 